\title{
Differences in social brain function in autism spectrum disorder are linked to the serotonin transporter
}

Nichol M.L. Wong ${ }^{1,2,3,4, *}$, Ottavia Dipasquale ${ }^{5}$, Federico Turkheimer ${ }^{5}$, James L. Findon ${ }^{1,2,6}$, Robert H. Wichers ${ }^{1,2,}$, Mihail Dimitrov ${ }^{1,2}$, Clodagh M. Murphy ${ }^{7}$, Vladimira Stoencheva ${ }^{7}$, Dene M. Robertson ${ }^{7}$, Declan G. Murphy ${ }^{1,2,3,8 \#}$, Eileen Daly ${ }^{1,2 \#}$, Grainne M. McAlonan ${ }^{1,2,3,8 \#}$

${ }^{1}$ Department of Forensic and Neurodevelopmental Sciences, Institute of Psychiatry, Psychology and Neuroscience, King's College London, United Kingdom

${ }^{2}$ Sackler Institute for Translational Neurodevelopment, Institute of Psychiatry, Psychology and Neuroscience, King's College London, United Kingdom

${ }^{3}$ Biomedical Research Centre for Mental Health at the Institute of Psychiatry, Psychology and Neuroscience and South London and Maudsley NHS Foundation Trust, United Kingdom ${ }^{4}$ Laboratory of Neuropsychology and Human Neuroscience, The University of Hong Kong, Hong Kong

${ }^{5}$ Department of Neuroimaging, Institute of Psychiatry, Psychology, and Neuroscience, King's College London, United Kingdom

${ }^{6}$ Department of Psychology, Institute of Psychiatry, Psychology and Neuroscience, King's College London, United Kingdom

${ }^{7}$ Behavioural Genetics Clinic, Adult Autism and ADHD Service, Behavioural and Developmental Psychiatry Clinical Academic Group, South London and Maudsley Foundation NHS Trust, UK

${ }^{8}$ MRC Centre for Neurodevelopmental Disorders, King's College London, United Kingdom

\section{\# Equal contribution}

\section{*Correspondence to:}

Nichol M.L. Wong, PhD

Room 658, The Jockey Club Tower, The University of Hong Kong Pokfulam Road, Hong Kong

Tel: (852) 3917-8927

Email: nichol.wong@hku.hk 


\section{Abstract}

Alterations in the serotonergic control of brain pathways responsible for facial-emotion processing in people with autism spectrum disorder (ASD) may be a target for intervention. However, the molecular underpinnings of autistic-neurotypical serotonergic differences are challenging to access in vivo. Receptor-Enriched Analysis of functional Connectivity by Targets (REACT) has helped define molecular-enriched fMRI brain networks based on a priori information about the spatial distribution of neurochemical systems from available PET templates. Here, we used REACT to estimate the dominant fMRI signal related to the serotonin transporter (5-HTT) distribution during processing of aversive facial expressions of emotion processing in adults with and without ASD. We first predicted a group difference in baseline (placebo) functioning of this system. We next used a single $20 \mathrm{mg}$ oral dose of citalopram, i.e. a serotonin reuptake inhibitor, to test the hypothesis that network activity in people with and without ASD would respond differently to inhibition of 5-HTT. To confirm the specificity of our findings, we also repeated the analysis with $5-\mathrm{HT}_{1 \mathrm{~A}}, 5-\mathrm{HT}_{1 \mathrm{~B}}, 5-\mathrm{HT}_{2 \mathrm{~A}}$, and $5-\mathrm{HT}_{4}$ receptor maps.

We found a baseline group difference in the 5-HTT-enriched response to faces in the ventromedial prefrontal cortex. A single oral dose of citalopram 'shifted' the response in the ASD group towards the neurotypical baseline but did not alter response in the control group.

Our findings suggest that the 5HTT-enriched functional network is dynamically different in ASD during processing of socially relevant stimuli. Whether this acute neurobiological response to citalopram in ASD translates to a clinical target will be an important next step. 


\section{Introduction}

Autism spectrum disorder (ASD) is neurodevelopmental condition that is characterised by social communication difficulties, in addition to restricted and repetitive behaviours ${ }^{1,2}$. Altered processing of socio-emotional stimuli may partly contribute to the phenotype. However, there are inconsistencies across the large number of fMRI studies of facial-emotion processing in ASD ${ }^{3-10}$ and a recent study in 205 individuals with ASD found no significant differences from neurotypical controls ${ }^{11}$. A possible explanation is that there is simply no common alteration in the neurobiology of social-emotional behaviour which is shared by all individuals on this heterogeneous spectrum ${ }^{12}$. Alternatively, it is also possible we have not adequately interrogated large-scale brain networks related to the neurochemical systems involved in complex higher-order behaviours ${ }^{13}$. This may be especially important for the serotonin (5-HT) system which has widespread regulatory effects across brain ${ }^{14}$, is involved in processing facial emotions ${ }^{15-17}$, and is strongly implicated in ASD ${ }^{18}$.

To support this contention, we previously reported preliminary evidence for central serotonin-based anomalies in $\mathrm{ASD}^{19}$, including the functional response to facial expressions of emotion ${ }^{8}$. Specifically, using fMRI we discovered that lowering 5-HT levels in individuals with ASD using a tryptophan depletion protocol shifts the brain functional response to emotional faces towards a more neurotypical pattern ${ }^{8}$. We have also confirmed that the manipulation of extracellular 5-HT levels by an acute dose of citalopram, a selective serotonin reuptake inhibitor (SSRI), alters the dynamics of the functional response to emotional faces in individuals with ASD, but not in neurotypicals, in the core social brain regions including amygdala, ventromedial prefrontal cortex (vmPFC), and striatum ${ }^{20}$. Taken together this suggests that the brain's 5-HT system is dynamically different in ASD in response to emotional faces, but we have yet to establish its molecular underpinnings.

The 5-HT transporter (5-HTT) is an integral plasma membrane protein that actively 
transports 5-HT for clearance and regulation of extracellular 5-HT. It is critical for 5-HT neurotransmission and homeostasis. Also, animal studies reported that 5-HTT knockout mice have autism-like behavioural phenotypes ${ }^{21}$. Moreover, a genetic study of the 5-HTT locus SLC6A4 identified multiple rare variants of 5-HTT with significant linkage to ASD ${ }^{22}$, albeit this finding could not be replicated in another group ${ }^{23}$. Finally, some ${ }^{24-26}$ (but not all ${ }^{27}$ ) human molecular imaging studies reported lower availability of regional 5-HTT in individuals with ASD that are related to their difficulties in social functioning. These prior studies were important first steps; however, a potentially crucial question has not been addressed - if the 5-HTT system in ASD functions differently.

Therefore, to understand if functional differences associated with the 5-HTT functional network contribute to altered processing of facial emotion in ASD, we employed the Receptor-Enriched Analysis of functional Connectivity by Targets (REACT) approach ${ }^{28}$. This method allowed us to weight fMRI analysis by the molecular distribution of 5-HTT in the brain, in order to better characterise the fMRI response to pharmacological manipulation of 5-HT during processing of facial expressions of emotion ${ }^{28}$. Hence, to test the hypothesis that there is a difference in adults with and without ASD, we used a 5-HTT PET template ${ }^{29}$ as a spatial regressor in a dual-regression analysis ${ }^{30}$.

In brief, on one of two study visits, either $20 \mathrm{mg}$ citalopram or placebo was administered orally to individuals with and without ASD in a double-blind, randomised order, 3 hours prior to an aversive facial-emotion processing fMRI task. In line with the literature and the mean 5-HTT-enriched functional map resulting from the analysis with REACT during the placebo condition, our functional network of interest comprised key social brain regions (i.e., amygdala, vmPFC, striatum and fusiform gyrus) ${ }^{31}$ involved in facial emotion processing.

However, 5-HT reuptake inhibition could also have secondary effects through 
constituent receptors of the serotonergic system (Riad et al., 2001; Selvaraj et al., 2014; Jackson and Moghaddam, 2018). Hence, to confirm the specificity of our findings, we also conducted supplementary analyses exploring also the 5- $\mathrm{HT}_{1 \mathrm{~A}^{-}}, 5-\mathrm{HT}_{1 \mathrm{~B}^{-}}, 5-\mathrm{HT}_{2 \mathrm{~A}^{-}}$, and 5- $\mathrm{HT}_{4-}$ enriched functional networks.

\section{Materials and Methods}

\section{Participants}

Forty right-handed adult males (19 with ASD and 21 neurotypical controls, 18-60 years old) were enrolled in this study. Individuals with a clinical diagnosis of ASD were recruited through the National Adult Autism Service at the Maudsley Hospital where diagnosis is a multi-disciplinary decision supported by the Autism Diagnostic Interview Revised (where an informant is available) and/or the Autism Diagnostic Observation Schedule $(\text { ADOS })^{35}$. Only individuals of IQ > 70 with no history of medical disorders that influence cognitive performance, no other major mental illnesses, genetic disorders associated with ASD, no alcohol or substance dependence, and not on any medication affecting the 5-HT system were included. Their scores on anxiety and depression were also measured by Hamilton Anxiety Rating Scale (HAM-A) and Hamilton Depression Rating Scale (HAM-D) respectively ${ }^{36,37}$ since these symptoms are common in ASD. All participants gave written, informed consent and this study received National Research Ethics approval from the Stanmore NHS Research Ethics Committee (reference: 14/LO/0663).

\section{Study design}

This study adopted a placebo-controlled, randomised, double-blind, repeatedmeasures, cross-over, case-control study design as part of a larger investigation into the brain 
response to 5-HT medications in ASD (https://clinicaltrials.gov Identifier: NCT04145076). Placebo and citalopram were allocated in a pseudo-randomised order, approximately half in each group attended a placebo visit before citalopram and the other half attended a citalopram visit before placebo, generated using an algorithm (https://www.random.org/). Participants completed two scanning visits that were separated by at least eight days, and they were administered an acute dose of encapsulated citalopram (20mg) or of encapsulated placebo (ascorbic acid) three hours before each scanning session as based on the pharmacokinetic properties of citalopram ${ }^{38}$.

During each scanning session, a face-emotion processing task ${ }^{20,39}$ was administered to participants. Briefly, the task consisted of four blocks of faces and four blocks of geometric shapes, with six five-second trials per block. Participants had to indicate which of the two images in the lower panel was identical to the target image in the upper panel in each trial. The facial images were either 'angry' or 'fearful'. Full details of the study design have been reported elsewhere ${ }^{20}$.

\section{MRI data acquisition and preprocessing}

The fMRI data were acquired on a 3 T General Electric Signa HD $\times$ Twinspeed scanner (Milwaukee, Wisc.) fitted with a quadrature birdcage head coil: TR $=2,000 \mathrm{~ms}, \mathrm{TE}=$ $30 \mathrm{~ms}, \mathrm{FOV}=192 \times 192 \mathrm{~mm}$, voxel size $=3 \times 3 \times 5 \mathrm{~mm}$, flip angle $=80^{\circ}$, number of time points $=135$. T1-weighted structural data was acquired in the sagittal planes: $\mathrm{TR}=7.312 \mathrm{~ms}$, $\mathrm{TE}=3.016 \mathrm{~ms}, \mathrm{FOV}=270 \times 270 \mathrm{~mm}^{2}$, matrix size $=256 \times 256$, slice thickness $=1.2 \mathrm{~mm}$, flip angle $=11^{\circ}$.

Each participant's fMRI images were first corrected for slice-timing and head movement with $F S L^{40}$. Participants with head movement of $\geq 3 \mathrm{~mm}$ in any plane, rotation $\geq$ 
$3^{\circ}$ in any direction, or with $>30 \%$ of their timepoints having framewise displacement (FD) > $0.2 \mathrm{~mm}^{41}$ were excluded, giving us a final sample of 21 controls and 13 individuals with ASD for subsequent analyses. A temporal high-pass filter at $128 \mathrm{~s}$ was applied and the fMRI data were smoothed by $8 \mathrm{~mm}$ full width at half-maximum kernel, normalised to the MNI space using their skull-stripped structural brain images and resampled to $2 \mathrm{~mm}^{3}$.

\section{5-HT-enriched functional response during task}

For the following analysis, we used the high-resolution in-vivo atlas of the distribution density of 5 -HTT ${ }^{29}$, that is characterised by high intensity in the entorhinal and insular cortices, subcortical regions, and the brainstem (Figure 1 A).

The atlas was used as a molecular template to estimate the 5-HTT-enriched functional response during the task in a two-step regression using the REACT approach ${ }^{28}$ with $F S L^{40}$. Details of this methodology can be found elsewhere ${ }^{28}$. In brief, in the first step, the molecular template is used as a spatial regressor to weight the fMRI signal in the grey matter (for this step the images were resampled at $1 \mathrm{~mm}^{3}$ ) and estimate the dominant blood-oxygenlevel-dependent (BOLD) fluctuation of the 5-HTT-enriched functional system at the subject level. The cerebellum was excluded at this stage as it was used as a reference region in the kinetic model for the estimation of the 5-HTT PET atlas ${ }^{29}$. In the second step, the resulting subject-specific time-series were incorporated as a temporal regressor of 5-HTT functional system into a generalised psycho-physiological interaction (gPPI) design to estimate the 5HTT-enriched Faces $>$ Shapes functional response of the brain (including the cerebellum; resampled at $2 \mathrm{~mm}^{3}$ ). Both data and design were demeaned in both steps for each subject; the design matrix was also normalised to the unit standard deviation in the second step. The design in the second step included the convolved Faces>Shapes regressor and its derivative, 
the convolved regressor with both Faces and Shapes blocks and its derivative, the dominant BOLD fluctuation within the 5-HTT map, the regressor of the interaction between the convolved Faces $>$ Shapes regressor and this BOLD fluctuation, six translational and rotational parameters of head movement, and the temporal masking regressor(s) of timepoints with FD $>0.2 \mathrm{~mm}$. Our regressor of interest was the regressor of interaction between the convolved Faces $>$ Shapes regressor and the dominant BOLD fluctuation within the 5-HTT map. The averaged 5-HTT-enriched BOLD functional response across participants is visualised in

\section{Figure 1 B.}

We also explored the functional response with a separate design that incorporated four more dominant BOLD fluctuation regressors within other 5-HT spatial PET maps (i.e., 5$\left.\mathrm{HT}_{1 \mathrm{~A}}, 5-\mathrm{HT}_{1 \mathrm{~B}}, 5-\mathrm{HT}_{2 \mathrm{~A}}, 5-\mathrm{HT}_{4}\right)$ in addition to the dominant BOLD fluctuation within the 5HTT map in the same model and the results are included in the Supplementary Information.

\section{Statistical analyses}

Demographics and scores in anxiety and depression were compared between groups using t-tests. Task behavioural performances in terms of response accuracy and reaction time (RT) between groups, stimuli, and drug conditions were compared using analysis of covariance (ANCOVA), controlling for their scores in anxiety and depression because of the group differences. Analyses were performed in $R$ (https://www.r-project.org) and significance was inferred when $\mathrm{p}<0.05$.

In the task functional response analyses, whole brain voxel-wise analysis was first performed in placebo condition to identify the baseline Faces>Shapes 5-HTT-enriched functional response across individuals with and without ASD using general linear modelling 
(and controlling for their scores in anxiety and depression). We next compared the 5-HTTenriched Faces $>$ Shapes functional response during placebo and citalopram conditions within our regions of interest (ROIs) - amygdala, vmPFC, striatum, and fusiform gyrus - between each group using randomise in FSL ${ }^{42}$. The ROIs were derived from Juelich histological atlas, vmPFC atlas of asymmetric and probabilistic cytoarchitectonic maps, Harvard-Oxford subcortical structural atlas and anatomical probability maps ${ }^{43-45}$. Given the group differences in anxiety and depression ratings, these scores were also entered as covariates. Significance was inferred when family-wise-error $(\mathrm{FWE})$ corrected $\mathrm{p}_{\mathrm{FWE}}<0.05$ using permutation testing with 5000 permutations and threshold-free cluster enhancement ${ }^{46}$.

Finally, with the caveat that this study was not powered to investigate multiple clinical measures, we carried out a preliminary exploration of whether an autistic individual's age, IQ, or ADOS subscores were related to their 5-HTT-enriched functional response using multiple linear regression. Significance was inferred when $\mathrm{p}<0.05$.

\section{Results}

\section{Demographics and clinical characteristics}

Individuals with and without ASD did not differ significantly in terms of age $\left(\mathrm{t}_{31}=\right.$ 0.892, $\mathrm{p}=0.379)$ and IQ $\left(\mathrm{t}_{31}=0.344, \mathrm{p}=0.733\right)$. As expected, however, individuals with ASD had higher scores in anxiety $\left(\mathrm{t}_{31}=3.298, \mathrm{p}=0.002\right)$ and depression $\left(\mathrm{t}_{19.2}=2.900, \mathrm{p}=\right.$ 0.009) ratings (Table 1).

\section{Task behavioural performance}

The accuracy of the individual responses during the task for the two drug conditions was investigated using a group $\times$ drug $\times$ stimuli factorial design and no interaction effects 
were identified ( $\mathrm{p}>0.05$ ) (Table 2). There was only a significant main effect of stimuli type, with individuals having higher accuracy in matching faces than shapes regardless of group $\left(\mathrm{F}_{1,28}=23.27, \mathrm{p}<0.001\right)$. Regarding response reaction times, no interaction effects were identified $(\mathrm{p}>0.05)$ but there was a significant main effect of stimuli type - with individuals matching faces more slowly than shapes regardless of group $\left(\mathrm{F}_{1,28}=15.14, \mathrm{p}=0.001\right)$ (Table 2).

\section{Baseline placebo 5-HTT-enriched functional response}

Using whole brain voxel-wise analysis, a significant increase in 5-HTT-enriched Faces $>$ Shapes response was identified at baseline placebo condition across individuals with and without ASD within regions including the superior temporal gyrus (STG), superior parietal lobule (SPL), posterior cingulate cortex (PCC), amygdala, vmPFC, striatum, and fusiform gyrus, confirming that the 5-HTT-enriched functional response was within our hypothesised ROIs ( $\left.\mathrm{p}_{\mathrm{FWE}}<0.05\right)$ (Figure 2; Table 3).

\section{Group comparisons of the 5-HTT-enriched functional response}

To investigate any differences in the action of citalopram in individuals with and without ASD, we performed an voxel-wise analysis on the 5-HTT-enriched functional connectivity within specific ROIs. At the baseline placebo condition, we observed a significant group difference (Controls>ASD) in the 5-HTT-enriched functional response in the right vmPFC (specifically within the medial orbitofrontal cortex [mOFC] and subgenual anterior cingulate cortex $[\mathrm{ACC}])\left(\mathrm{k}=70, \mathrm{p}_{\text {peak }}=0.039, \mathrm{MNI}_{\mathrm{xyz}}=[16,22,-18]\right)$; in contrast, there was no ASD-Controls group difference in the citalopram condition. Although we did not find any significant group $\times$ drug interaction effect across voxels, post-hoc analyses 
revealed that citalopram increased the 5-HTT-enriched functional response in ASD $(\mathrm{p}=$ 0.018 ) to a response level similar to the neurotypical controls $(\mathrm{p}>0.05)$. There was no significant response difference between baseline placebo and citalopram in neurotypical controls $(\mathrm{p}=0.541)$ (Figure 3 ). To confirm the specificity of the findings, we repeated the analysis by including all five dominant BOLD fluctuations of the 5-HT systems in the same model and found similar differences in 5-HTT-enriched functional response, suggesting that the response observed is specific to dominant BOLD fluctuations within 5-HTT map and could not be explained by other 5-HT receptors. Details are reported in the Supplementary Information.

\section{Individual variations and 5-HTT-enriched functional response in ASD}

We also explored whether age, IQ, and clinical characteristics might be related to the citalopram-induced changes in 5-HTT-enriched functional response in individuals with ASD. Citalopram caused the greatest change in the mean functional response across the right subgenual ACC $(B=-0.697, p=0.034)$ in autistic individuals with the least communication difficulties. Age, IQ, scores of anxiety and depression were not related to citalopram-induced changes in 5-HTT-enriched functional response in ASD, suggesting that the functional differences in the 5-HTT social brain network are not due to co-occurring mental health difficulties or overall intellectual ability.

\section{Discussion}

We found a baseline ASD-neurotypical group difference in the function of a 'social brain' 5-HTT network. However, following a single oral dose of citalopram (which inhibits the 5-HTT), the response within vmPFC in the ASD group was no longer different from the 
neurotypical baseline (placebo). Thus, the functional dynamics of 5-HTT pathways involved in facial emotion processing are altered in ASD but can be 'shifted' to a neurotypical placebo profile by inhibition of 5-HTT.

Specifically, face-emotion processing activated a 5-HTT-enriched functional circuit across the STG, PCC, amygdala, vmPFC, striatum, and fusiform gyrus, i.e. regions which underpin face and facial emotion processing ${ }^{31}$. However, we observed a significantly lower response to emotional faces in the mOFC and subgenual ACC within the vmPFC in individuals with ASD compared to neurotypical controls at baseline (placebo). The medial prefrontal cortex (mPFC) is crucial to the theory of mind, which is at least partly dependent upon facial-emotion processing ${ }^{47}$. Therefore, our placebo result converges with prior studies that reported altered vmPFC response during processing of facial emotions in $\operatorname{ASD}^{5,10}$, but extends to support a critical role for 5-HTT in ASD.

Our results reveal a potential functional difference in 5-HTT during facial emotion processing. This was confirmed by the effect of citalopram which acts on 5-HTT (in addition to other 5HT receptors) and which increased the vmPFC response in individuals with ASD to a similar level to that observed in neurotypical adults. In contrast, there was no change in brain function in neurotypical adults as measured 3 hours following the 5-HT challenge by the acute citalopram dose. This shift of functional response in individuals with ASD to a more neurotypical pattern was broadly similar to that observed in our previous study of tryptophan depletion in people with and without $\mathrm{ASD}^{8}$. A tryptophan depletion protocol lowers 5-HT levels and shifts the ASD individuals' response to fearful and sad faces within regions including $\mathrm{mPFC}$ to a neurotypical pattern ${ }^{8}$. At first glance it is challenging to reconcile the similar actions of 5-HT reduction through acute tryptophan depletion and 5-HTT inhibition by citalopram, which should increase 5-HT levels, in ASD. However, recent re-appraisal of the action of acute tryptophan depletion has concluded that there is "no convincing evidence" 
that the procedure alters central 5-HT release and/or neuronal activity ${ }^{48}$. Indeed, the effect of altering tryptophan levels on 5-HT levels "depends critically on the circumstances in which it is given" ${ }^{49}$. An acute citalopram dose has previously been shown to be similar to the effect of acute tryptophan depletion in behavioural tasks ${ }^{50,51}$. Hence, to probe the 5-HT system, citalopram is much more specific as it has high affinity for 5 -HTT ${ }^{52}$. This adds confidence that our findings are best explained by a functional difference in the 5-HTT system in ASD.

How functional differences in the 5-HTT arise in ASD is not clear. The 5-HT system is essential for brain development and is also vulnerable to multiple influences during the critical antenatal period. For example, foetal exposure to pharmacologic (e.g. 5-HT reuptake inhibitors) and/or genetic (functional polymorphisms) differences in 5-HTT function (in mother or foetus) are linked with ASD and related neurodevelopmental outcomes ${ }^{53,54}$. Consequently, inhibiting the 5-HTT activity with SSRIs has been reported to be a useful intervention in children with such complex neurodevelopmental conditions ${ }^{55}$. The most recent PET investigation of 5-HTT in ASD ${ }^{26}$ reported lower availability across the brain, but especially in the ACC; lower 5-HTT availability in ACC was also correlated to the extent of difficulties in social functioning ${ }^{25}$. It is possible that lower levels of a target for citalopram may mean the response to $20 \mathrm{mg}$ dose is easier to detect; i.e. there is less redundancy in the system. This also chimes with evidence that people with ASD are more sensitive to the side effects of SSRI ${ }^{56}$ and advice to start SSRIs at a lower dose in $\mathrm{ASD}^{55}$.

It is noteworthy that the response to citalopram observed in ASD here could not be attributed to the presence of common co-occurring conditions (i.e., anxiety and depression) or current use of medicines impacting on 5-HT. Instead, we found that symptoms on the autism spectrum - mainly on the communication domain - were related to the shift in 5-HTTenriched functional response in the vmPFC. We observed that individuals with ASD who had less communication difficulties had a greater shift in response to citalopram challenge. In 
addition, scrutiny of the individual responses indicates that not everyone in the ASD group responded to citalopram in the same direction. This may have important clinical applications as it indicates that not every individual on the heterogeneous autism spectrum will respond in the same way to 5-HT treatment. It lends support to the current guidelines that low dose of SSRI should be used in individuals with ASD, titrating up gradually with careful monitoring 57.

\section{Limitations}

There are several limitations of this study. The analyses were based on a relatively small sample size because we adhered to strict recruitment criteria and applied strict motion correction criteria. However, a strength of our study was the repeated visits design which increased power by reducing heterogeneity of the sample. Our hypothesis was limited to the 5-HTT. Future studies could also test the functional response in relation to other receptor density maps, such as GABA and glutamate, which also influence brain function and are modulated by 5 -HT ${ }^{14}$. We did not examine a more general impact of 5-HT modulation on cognitive and affective functioning ${ }^{58}$. Therefore, caution is warranted before generalising the findings to other processes such as cognitive inhibition. This multimodal REACT approach offers specific insight into the functional response enriched by the 5-HTT system. However, it is noteworthy that the PET molecular templates used here were from a study with typically developed controls ${ }^{29}$ and although recent evidence suggests lower availability of 5-HTT in ASD ${ }^{24-26}$, there is disagreement ${ }^{27}$ and we cannot say what the exact pattern of 5-HTT distribution was in either controls or ASD participants in this study. Other limitations should also be noted, including the use of single-sex sample in order to increase sample homogeneity and to avoid inadvertent exposure of pregnant females to SSRI ${ }^{20}$. Hence, it is important to extend our work in future to include females with ASD. 


\section{Conclusions}

This is the first study to apply the multimodal REACT approach to a task-fMRI paradigm to enrich the analysis by accounting for the distribution of 5-HTT, main target of citalopram. This provided a novel insight into the functional dynamics of the 5-HTT system in ASD during social information processing. An ASD-neurotypical group difference in functional response to facial emotions in the 5-HTT-related functional circuit was found, but disappeared following citalopram administration that leads to 5-HTT inhibition. The response to citalopram was observed only in the ASD group and suggests that the 5-HTT is dynamically different during processing of salient social stimuli in ASD. This may constitute a treatment target which should be explored in future clinical studies.

\section{Acknowledgement}

The authors would like to thank all the volunteers for their participation.

The authors acknowledge support from the Maudsley Pharmacy Department and the National Autism Service for Adults at the South London, the National Institute for Health Research (NIHR) Biomedical Research Centre for Mental Health at South London and Maudsley NHS Foundation Trust and Institute of Psychiatry, Psychology and Neuroscience King's College London. The views expressed are those of the author(s) and not necessarily those of the IMI, NHS, the NIHR or the Department of Health. Support has also been received funding from the Sackler Institute for Translational Neurodevelopment at King's College London, the MRC Centre for Neurodevelopmental Disorders at King's College London and the Innovative Medicines Initiative 2 Joint Undertaking under grant agreement No 777394 for the project AIMS-2-TRIALS. This Joint Undertaking receives support from 
bioRxiv preprint doi: https://doi.org/10.1101/2021.05.28.446151; this version posted May 28, 2021. The copyright holder for this preprint (which

was not certified by peer review) is the author/funder, who has granted bioRxiv a license to display the preprint in perpetuity. It is made available under aCC-BY-NC-ND 4.0 International license.

NML Wong et al.

5-HTT function in autism emotion processing

the European Union's Horizon 2020 research and innovation programme and EFPIA and AUTISM SPEAKS, Autistica, SFARI.

\section{Conflict of interest}

Professor D. G. Murphy has received research funding from, and served as an advisor to, Roche and Servier, that is unrelated to this study. Professor Grainne M. McAlonan has received current funding from Compass and past funding from GW Pharma, that are unrelated to this study. The other authors declare no conflict of interest. 


\section{References}

1. Lai, M. C., Lombardo, M.V. \&Baron-Cohen, S. Autism. Lancet 383, 896-910 (2014).

2. American Psychiatric Association. Diagnostic and statistical manual of mental disorders. Arlington (2013). doi:10.1176/appi.books.9780890425596.744053.

3. Dalton, K. M. et al. Gaze fixation and the neural circuitry of face processing in autism. Nat. Neurosci. 8, 519-526 (2005).

4. Critchley, H. D. et al. The functional neuroanatomy of social behaviour. Brain 123, 2203-2212 (2000).

5. Ashwin, C., Baron-Cohen, S., Wheelwright, S., O’Riordan, M. \&Bullmore, E. T. Differential activation of the amygdala and the 'social brain' during fearful faceprocessing in Asperger Syndrome. Neuropsychologia 45, 2-14 (2007).

6. Pinkham, A. E., Hopfinger, J. B., Pelphrey, K. A., Piven, J. \&Penn, D. L. Neural bases for impaired social cognition in schizophrenia and autism spectrum disorders. Schizophr. Res. 99, 164-175 (2008).

7. Bullmore, E. T. et al. The amygdala theory of autism. Neurosci. Biobehav. Rev. 24, 355-364 (2002).

8. Daly, E. M. et al. Serotonin and the neural processing of facial emotions in adults with autism: An fMRI study using acute tryptophan depletion. Arch. Gen. Psychiatry 69, 1003-1013 (2012).

9. Daly, E. et al. Effects of acute tryptophan depletion on neural processing of facial expressions of emotion in humans. Psychopharmacology (Berl). 210, 499-510 (2010).

10. Wicker, B. et al. Abnormal cerebral effective connectivity during explicit emotional processing in adults with autism spectrum disorder. Soc. Cogn. Affect. Neurosci. 3, 135-143 (2008). 
11. Moessnang, C. et al. Social brain activation during mentalizing in a large autism cohort: the Longitudinal European Autism Project. Mol. Autism 11, 17 (2020).

12. Lombardo, M.V., Lai, M. C. \&Baron-Cohen, S. Big data approaches to decomposing heterogeneity across the autism spectrum. Mol. Psychiatry 24, 1435-1450 (2019).

13. Cremers, H. R., Wager, T. D. \&Yarkoni, T. The relation between statistical power and inference in fMRI. PLoS One 12, 1-20 (2017).

14. Ciranna, L. Serotonin as a Modulator of Glutamate- and GABA-Mediated Neurotransmission: Implications in Physiological Functions and in Pathology. Curr. Neuropharmacol. 4, 101-114 (2006).

15. Murphy, S. E., Longhitano, C., Ayres, R. E., Cowen, P. J. \&Harmer, C. J. Tryptophan supplementation induces a positive bias in the processing of emotional material in healthy female volunteers. Psychopharmacology (Berl). 187, 121-130 (2006).

16. Harmer, C. J., Rogers, R. D., Tunbridge, E., Cowen, P. J. \&Goodwin, G. M. Tryptophan depletion decreases the recognition of fear in female volunteers. Psychopharmacology (Berl). 167, 411-417 (2003).

17. Selvaraj, S. et al. Effect of Citalopram on Emotion Processing in Humans: A Combined 5-HT1A [11C]CUMI-101 PET and Functional MRI Study. Neuropsychopharmacology 43, 655-664 (2018).

18. Deutsch, S. I. \&Raffaele, C. T. Understanding facial expressivity in autism spectrum disorder: An inside out review of the biological basis and clinical implications. Prog. Neuro-Psychopharmacology Biol. Psychiatry 88, 401-417 (2019).

19. Wichers, R. et al. Modulation of brain activation during executive functioning in autism with citalopram. Transl. Psychiatry 9, 286 (2019). 
20. Wong, N. M. L. et al. Serotonin differentially modulates the temporal dynamics of the limbic response to facial emotions in male adults with and without autism spectrum disorder (ASD): a randomised placebo-controlled single-dose crossover trial.

Neuropsychopharmacology (2020) doi:10.1038/s41386-020-0693-0.

21. Murphy, D. L. \&Lesch, K. P. Targeting the murine serotonin transporter: Insights into human neurobiology. Nat. Rev. Neurosci. 9, 85-96 (2008).

22. Sutcliffe, J. S. et al. Allelic heterogeneity at the serotonin transporter locus (SLC6A4) confers susceptibility to autism and rigid-compulsive behaviors. Am. J. Hum. Genet. 77, 265-279 (2005).

23. Sakurai, T. et al. A large-scale screen for coding variants in SERT/SLC6A4 in autism spectrum disorders. Autism Res. 1, 251-257 (2008).

24. Makkonen, I., Riikonen, R., Kokki, H., Airaksinen, M. M. \&Kuikka, J. T. Serotonin and dopamine transporter binding in children with autism determined by SPECT. Dev. Med. Child Neurol. 50, 593-597 (2008).

25. Nakamura, K. et al. Brain serotonin and dopamine transporter bindings in adults with high-functioning autism. Arch. Gen. Psychiatry 67, 59-68 (2010).

26. Andersson, M. et al. Serotonin transporter availability in adults with autism-a positron emission tomography study. Mol. Psychiatry (2020).

27. Girgis, R. R. et al. The 5-HT 2A receptor and serotonin transporter in Asperger's Disorder: A PET study with [ 11C]MDL 100907 and [ 11C]DASB. Psychiatry Res. Neuroimaging 194, 230-234 (2011).

28. Dipasquale, O. et al. Receptor-Enriched Analysis of functional connectivity by targets (REACT): A novel, multimodal analytical approach informed by PET to study the pharmacodynamic response of the brain under MDMA. Neuroimage 195, 252-260 
(2019).

29. Beliveau, V. et al. A high-resolution in vivo atlas of the human brain's serotonin system. J. Neurosci. 37, 120-128 (2017).

30. Nickerson, L. D., Smith, S. M., Öngür, D. \&Beckmann, C. F. Using dual regression to investigate network shape and amplitude in functional connectivity analyses. Front. Neurosci. 11, 115 (2017).

31. Gobbini, M. I. \&Haxby, J.V. Neural systems for recognition of familiar faces. Neuropsychologia 45, 32-41 (2007).

32. Riad, M., Watkins, K. C., Doucet, E., Hamon, M. \&Descarries, L. Agonist-induced internalization of serotonin-1A receptors in the dorsal raphe nucleus (autoreceptors) but not hippocampus (heteroreceptors). J. Neurosci. 21, 8378-8386 (2001).

33. Selvaraj, S. et al. Presynaptic serotoninergic regulation of emotional processing: A multimodal brain imaging study. Biol. Psychiatry 78, 563-571 (2014).

34. Jackson, M. E. \&Moghaddam, B. Amygdala Regulation of Nucleus Accumbens Dopamine Output is Governed by the Prefrontal Cortex. J. Neurosci. 21, 676-681 (2018).

35. Lord, C. et al. Austism diagnostic observation schedule: A standardized observation of communicative and social behavior. J. Autism Dev. Disord. 19, 185-212 (1989).

36. Hamilton, M. The assessment of anxiety states by rating. Br. J. Med. Psychol. 32, 5055 (1959).

37. Hamilton, M. A rating scale for depression. J. Neurol. Neurosurg. Psychiatry 23, 5663 (1960).

38. Sangkuhl, K., Klein, T. E. \&Altman, R. B. PharmGKB summary: Citalopram 
pharmacokinetics pathway. Pharmacogenet. Genomics 21, 769-792 (2011).

39. Hariri, A. R., Tessitore, A., Mattay, V. S., Fera, F. \&Weinberger, D. R. The amygdala response to emotional stimuli: A comparison of faces and scenes. Neuroimage 17, $317-323$ (2002).

40. Jenkinson, M., Beckmann, C. F., Behrens, T. E. J., Woolrich, M. W. \&Smith, S. M. FSL. Neuroimage 62, 782-790 (2012).

41. Power, J. D., Barnes, K. A., Snyder, A. Z., Schlaggar, B. L. \&Petersen, S. E. Spurious but systematic correlations in functional connectivity MRI networks arise from subject motion. Neuroimage 59, 2142-2154 (2012).

42. Winkler, A. M., Ridgway, G. R., Webster, M. A., Smith, S. M. \&Nichols, T. E. Permutation inference for the general linear model. Neuroimage 92, 381-397 (2014).

43. Eickhoff, S. B. et al. A new SPM toolbox for combining probabilistic cytoarchitectonic maps and functional imaging data. Neuroimage 25, 1325-1335 (2005).

44. Mackey, S. \&Petrides, M. Architecture and morphology of the human ventromedial prefrontal cortex. Eur. J. Neurosci. 40, 2777-2796 (2014).

45. Desikan, R. S. et al. An automated labeling system for subdividing the human cerebral cortex on MRI scans into gyral based regions of interest. Neuroimage 31, 968-980 (2006).

46. Smith, S. M. \&Nichols, T. E. Threshold-free cluster enhancement: Addressing problems of smoothing, threshold dependence and localisation in cluster inference. Neuroimage 44, 83-98 (2009).

47. Schurz, M., Radua, J., Aichhorn, M., Richlan, F. \&Perner, J. Fractionating theory of mind: A meta-analysis of functional brain imaging studies. Neurosci. Biobehav. Rev. 42, 
NML Wong et al.

5-HTT function in autism emotion processing

9-34 (2014).

48. vanDonkelaar, E. L. et al. Mechanism of acute tryptophan depletion: Is it only serotonin. Mol. Psychiatry 16, 695-713 (2011).

49. Young, S. N. \&Teff, K. L. Tryptophan availability, 5ht synthesis and 5HT function. Prog. Neuropsychopharmacol. Biol. Psychiatry 13, 373-379 (1989).

50. Selvaraj, S. et al. Measuring endogenous changes in serotonergic neurotransmission in humans: A [11C] CUMI-101 PET challenge study. Mol. Psychiatry 17, 1254-1260 (2012).

51. Chamberlain, S. R. et al. Neurochemical modulation of response inhibition and probabilistic learning in humans. Science (80-. ). 311, 861-863 (2006).

52. Hyttel, J. Pharmacological characterization of selective serotonin reuptake inhibitors (SSRIs). Int. Clin. Psychopharmacol. 9, 19-26 (1994).

53. Croen, L. A., Grether, J. K., Yoshida, C. K., Odouli, R. \&Hendrick, V. Antidepressant use during pregnancy and childhood autism spectrum disorders. Arch. Gen. Psychiatry 68, 1104-1112 (2011).

54. Garbarino, V. R., Gilman, T. L., Daws, L. C. \&Gould, G. G. Extreme enhancement or depletion of serotonin transporter function and serotonin availability in autism spectrum disorder. Pharmacol. Res. 140, 85-99 (2019).

55. Reiersen, A. M. \&Todd, R. D. Co-occurrence of ADHD and autism spectrum disorders: Phenomenology and treatment. Expert Rev. Neurother. 8, 657-669 (2008).

56. Reddihough, D. S. et al. Effect of Fluoxetine on Obsessive-Compulsive Behaviors in Children and Adolescents with Autism Spectrum Disorders: A Randomized Clinical Trial. JAMA - J. Am. Med. Assoc. 322, 1561-1569 (2019). 
bioRxiv preprint doi: https://doi.org/10.1101/2021.05.28.446151; this version posted May 28, 2021. The copyright holder for this preprint (which

was not certified by peer review) is the author/funder, who has granted bioRxiv a license to display the preprint in perpetuity. It is made available under aCC-BY-NC-ND 4.0 International license.

NML Wong et al.

5-HTT function in autism emotion processing

57. Howes, O. D. et al. Autism spectrum disorder: Consensus guidelines on assessment, treatment and research from the British Association for Psychopharmacology. $J$.

Psychopharmacol. 32, 3-29 (2018).

58. Del-Ben, C. M. et al. The effect of citalopram pretreatment on neuronal responses to neuropsychological tasks in normal volunteers: An fMRI study.

Neuropsychopharmacology 30, 1724-1734 (2005). 
bioRxiv preprint doi: https://doi.org/10.1101/2021.05.28.446151; this version posted May 28, 2021. The copyright holder for this preprint (which

was not certified by peer review) is the author/funder, who has granted bioRxiv a license to display the preprint in perpetuity. It is made available under aCC-BY-NC-ND 4.0 International license.

NML Wong et al.

5-HTT function in autism emotion processing

Table 1. Demographics and clinical characteristics of the study sample

\begin{tabular}{rcccc}
\hline & $\begin{array}{c}\text { ASD } \\
(\mathrm{n}=13)\end{array}$ & $\begin{array}{c}\text { Controls } \\
(\mathrm{n}=21)\end{array}$ & $\boldsymbol{T}$ & $\boldsymbol{p}$ \\
\hline Demographics & & & & \\
Age (years) & $30.31(11.54)$ & $27.05(9.34)$ & 0.892 & 0.379 \\
Intelligence quotient & $112.77(18.36)$ & $114.45(9.73)$ & 0.344 & 0.733 \\
Clinical \\
characteristics
\end{tabular}

The means are presented with standard deviations in parenthesis.

HAM-A=Hamilton Anxiety Rating Scale; HAM-D=Hamilton Depression Rating Scale;

ADOS-C=Autism Diagnostic Observation Schedule-Communication domain;

ADOS-S=Autism Diagnostic Observation Schedule-Reciprocal Social Interaction domain 
bioRxiv preprint doi: https://doi.org/10.1101/2021.05.28.446151; this version posted May 28, 2021. The copyright holder for this preprint (which

was not certified by peer review) is the author/funder, who has granted bioRxiv a license to display the preprint in perpetuity. It is made available under aCC-BY-NC-ND 4.0 International license.

NML Wong et al.

5-HTT function in autism emotion processing

Table 2. Behavioural performance of the study sample during the task

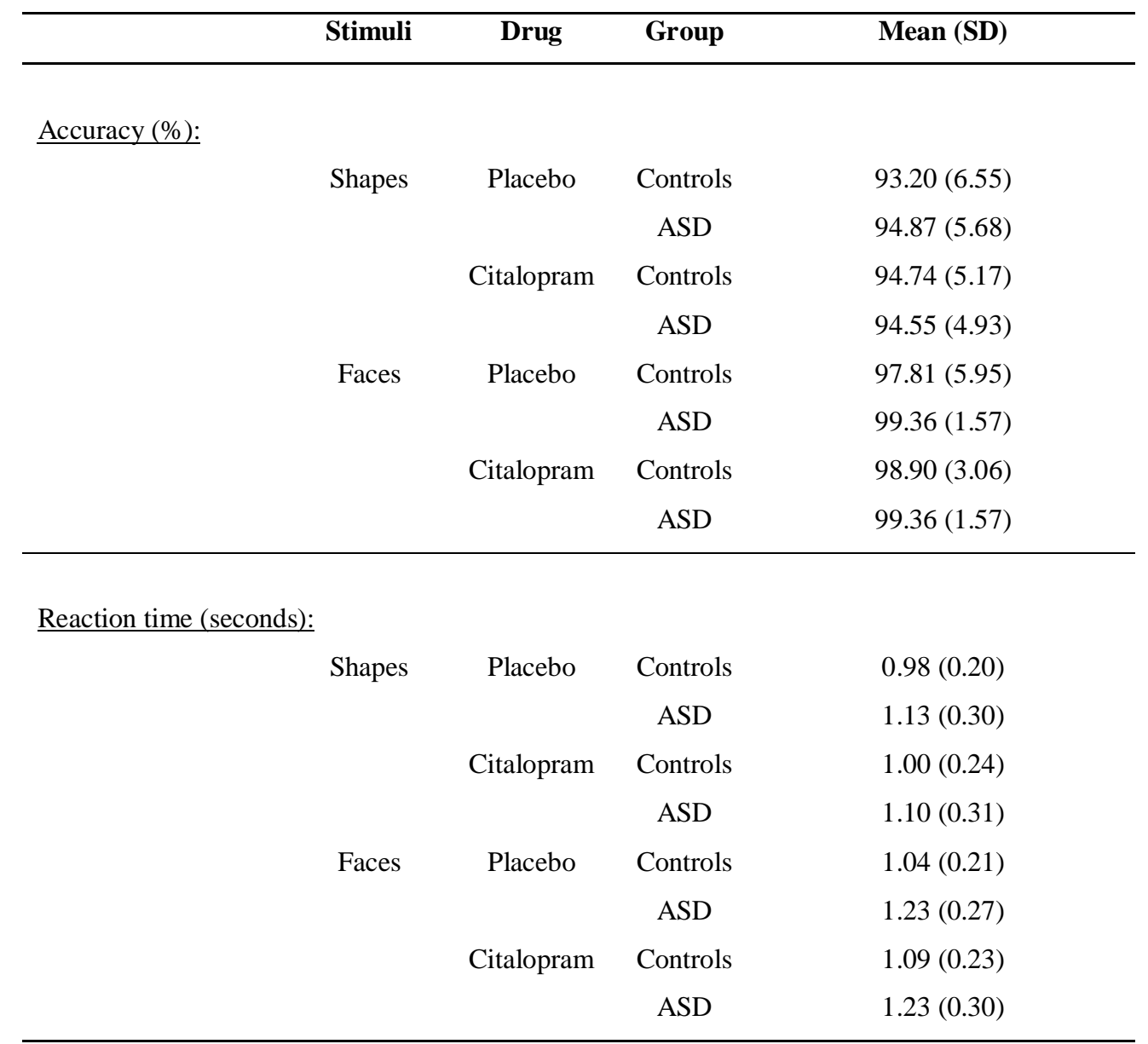

The means and standard deviations (SD) are presented. 
bioRxiv preprint doi: https://doi.org/10.1101/2021.05.28.446151; this version posted May 28, 2021. The copyright holder for this preprint (which

was not certified by peer review) is the author/funder, who has granted bioRxiv a license to display the preprint in perpetuity. It is made available under aCC-BY-NC-ND 4.0 International license.

NML Wong et al.

5-HTT function in autism emotion processing

Table 3. The clusters with increased 5-HTT-enriched Faces>Shapes functional response at baseline placebo condition across the whole sample

\begin{tabular}{cccccc}
\hline Cluster & Size (voxels) & $\boldsymbol{X}$ & MNI coordinates & $\boldsymbol{Z}$ & p peak \\
& & 54 & -16 & 2 & 0.037 \\
$\mathbf{1}$ & 48525 & -28 & -52 & 34 & 0.049 \\
$\mathbf{2}$ & 379 & 10 & -38 & 26 & 0.050 \\
$\mathbf{3}$ & 70 & -28 & -32 & 18 & 0.050 \\
$\mathbf{4}$ & 69 & &
\end{tabular}


bioRxiv preprint doi: https://doi.org/10.1101/2021.05.28.446151; this version posted May 28, 2021. The copyright holder for this preprint (which

was not certified by peer review) is the author/funder, who has granted bioRxiv a license to display the preprint in perpetuity. It is made available under aCC-BY-NC-ND 4.0 International license.

(A)

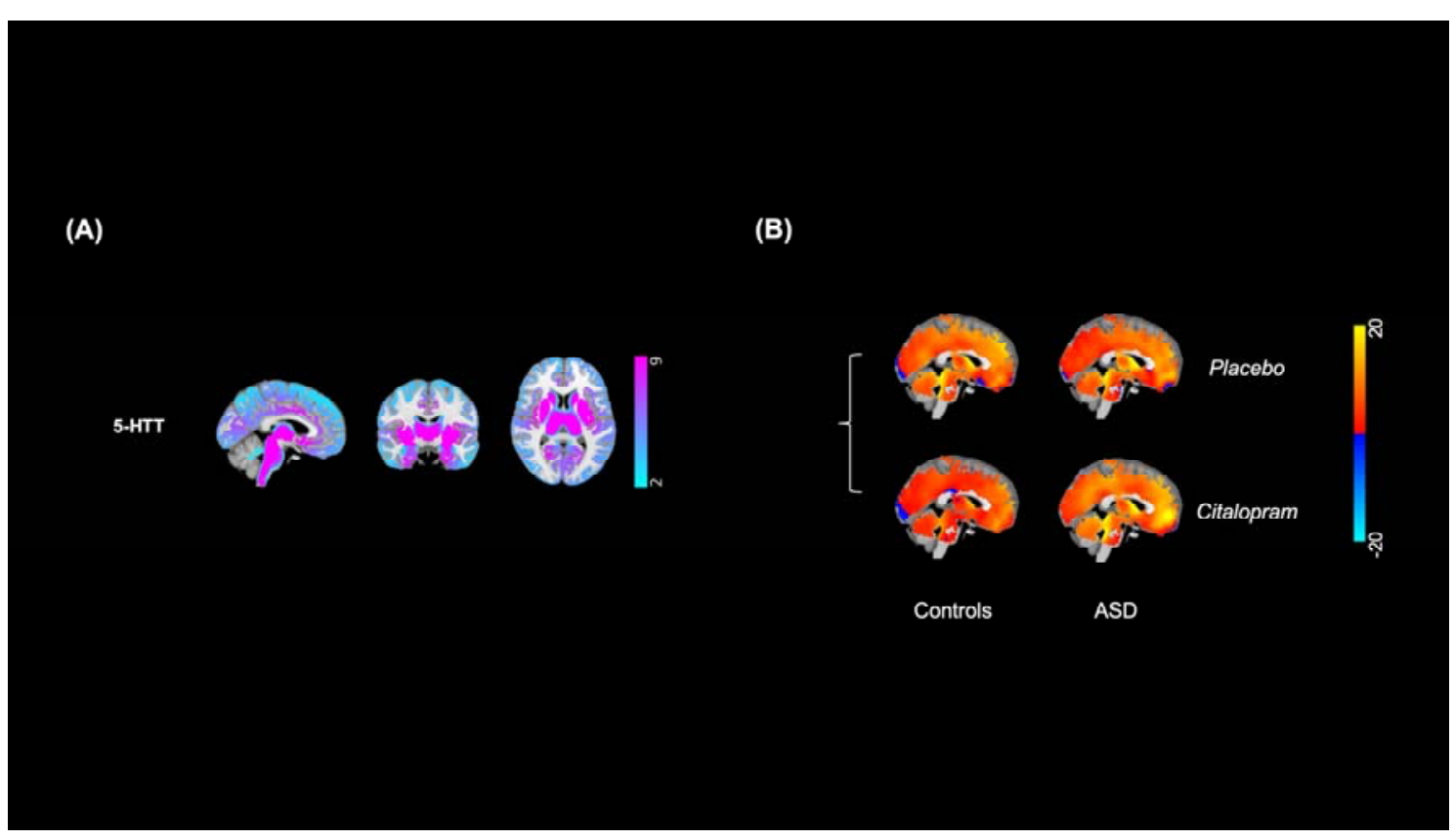

Figure 1. (A) The in-vivo atlas of the serotonin transporter $\left(5-\mathrm{HT}_{\mathrm{T}}\right)$ is presented with its corresponding density distribution on a colour scale. (B) The 5-HTT-enriched functional maps corresponding to the interaction between the convolved Faces $>$ Shapes regressor and the dominant blood-oxygen-level-dependent (BOLD) fluctuation within 5-HTT map were averaged in individuals with and without autism spectrum disorder (ASD) in each drug condition for visualisation. 
bioRxiv preprint doi: https://doi.org/10.1101/2021.05.28.446151; this version posted May 28, 2021. The copyright holder for this preprint (which was not certified by peer review) is the author/funder, who has granted bioRxiv a license to display the preprint in perpetuity. It is made available under aCC-BY-NC-ND 4.0 International license.

NML Wong et al.

5-HTT function in autism emotion processing

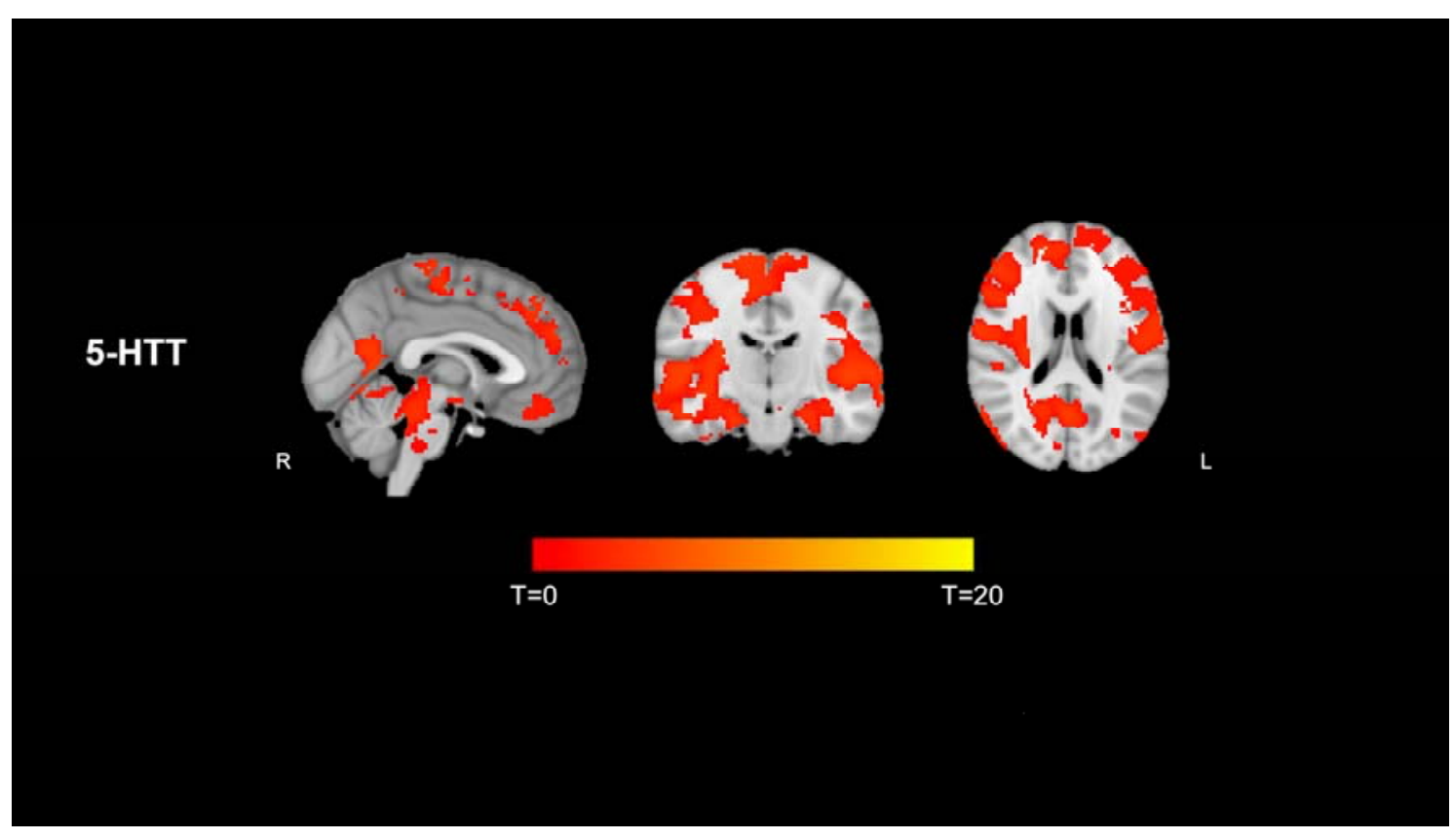

Figure 2. The significant clusters of increased serotonin transporter (5-HTT)-enriched Faces $>$ Shapes functional response across individuals with and without autism spectrum disorder (ASD) are overlaid on the anatomical brain. $\mathrm{L}=\mathrm{Left}, \mathrm{R}=\mathrm{Right}$. 
bioRxiv preprint doi: https://doi.org/10.1101/2021.05.28.446151; this version posted May 28, 2021. The copyright holder for this preprint (which was not certified by peer review) is the author/funder, who has granted bioRxiv a license to display the preprint in perpetuity. It is made available under aCC-BY-NC-ND 4.0 International license.

NML Wong et al.

5-HTT function in autism emotion processing

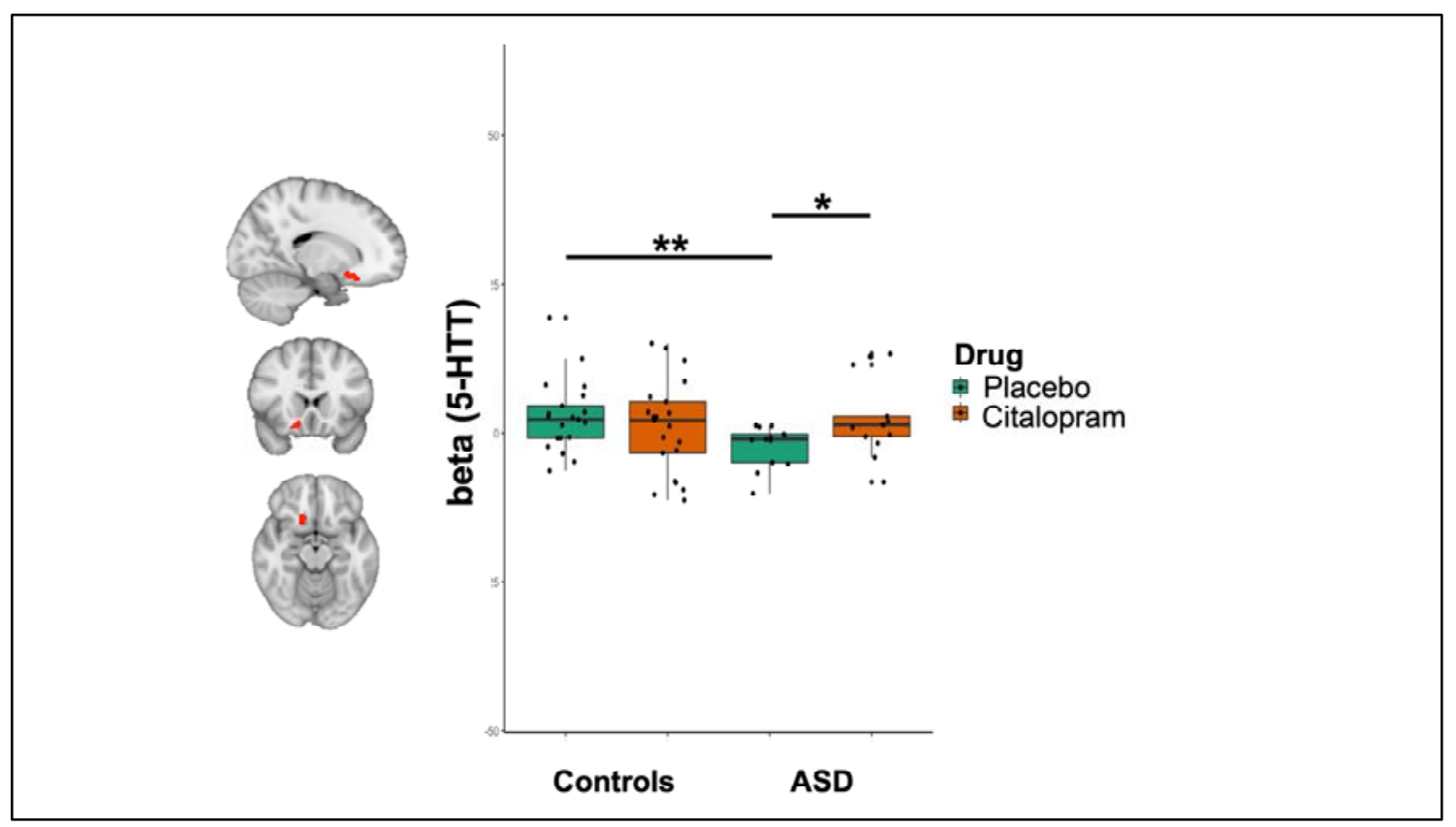

Figure 3. Significantly higher serotonin transporter (5-HTT)-enriched Faces $>$ Shapes response in neurotypical controls compared to individuals with autism spectrum disorder (ASD) within the right ventromedial prefrontal cortex (vmPFC). Post-hoc analysis revealed that citalopram significantly increased the 5-HTT-enriched functional response in ASD. The results are demonstrated in a box plot. $* \mathrm{p}<0.05, * * \mathrm{p}<0.01$. 